\title{
Mind the Gap: Women in STEM Career Breaks
}

\author{
Catherine Mavriplis', Rachelle Heller², Cheryl Beil³, Kim Dam4, \\ Natalya Yassinskaya ${ }^{5}$, Megan Shaw ${ }^{6}$, Charlene Sorensen ${ }^{7}$
}

\begin{abstract}
The slow advancement of women in scientific fields remains a persistent problem, especially in academia. Highly trained doctoral women in the sciences drop out of the academic pipeline for a variety of reasons that are poorly documented. This paper reports on a qualitative exploratory study based on structured interviews with 15 women who have taken career breaks after receiving their science, technology, engineering or mathematics (STEM) PhD, but wish to re-enter the academic career track. The study aims to understand the pressures that contribute to taking such breaks, how women remain connected (or not) to their field during breaks and how re-entering the field after a career break could be facilitated. Suggestions based on the interviews include career development workshops and networking opportunities for women in breaks, as well as systemic changes such as reduced fees for society membership and conferences, changes in the way resumés are reviewed by faculty search committees, and in the design and implementation of maternity and child care leave policies.
\end{abstract}

Keywords: career breaks; STEM research and education; career pathways; career gender differences; work-life balance; careers in higher education.

\footnotetext{
' Department of Mechanical Engineering, University of Ottawa, 16I Louis Pasteur, Ottawa, Ontario, Canada KIN 6N5. Phone: + I 6135625800 x896I. Email: Catherine.Mavriplis@uottawa.ca

2 Department of Computer Science, George Washington University, 2100 Foxhall Rd. NW, Washington, DC, USA 20007. Phone: + I 202242 6698. Email: sheller@gwu.edu

${ }^{3}$ Academic Planning, Institutional Research, and Assessment, George Washington University, 2 I2I Eye St. NW, Washington, DC, USA 20052., Phone: + I 202994 67I2. Email: cbeil@gwu.edu

${ }^{4}$ Academic Planning and Assessment, George Washington University, 2 I 2 I Eye St. NW, Washington, DC, USA 20052.

Phone: + I 202994 2103. Email: madmik@gwu.edu

${ }^{5}$ Human Resource Development Program, George Washington University, 2 I 34 G St. NW, Washington, DC, USA 20052.

Phone: + 202994 3410. Email: natalya.yassinskaya@gmail.com

${ }^{6}$ Department of Organizational Sciences and Communication, George Washington University, $6002 I^{\text {st }}$ St. NW, Washington, DC, USA 20052. Phone: + 202994 1878. Email: shawmeg@gmail.com

7 Department of Chemistry and Physics, Gallaudet University, 800 Florida Avenue, Washington, DC, USA 20002.

Phone: + 20265 I 5205. Email: charlene.sorensen@gallaudet.edu
} 


\section{Background}

Women in Science, Technology, Engineering and Mathematics (STEM) academia have been making significant strides to improve their numbers over the last few decades. Certainly, the number of "science and engineering" (as defined by the US National Science Foundation i.e. including the social sciences) doctorates awarded to women has increased dramatically in these fields, accounting now for $50 \%$ of the science and engineering doctorates awarded in the US in 2007 up from 20\% in 1978 (NSB, 2010). Employment of women in academia remains high in these fields, but it is often in untenured or part-time positions (NSB, 2010). Women's transition from pre-tenure to tenure-track professorships can be helped by some initiatives, such as tailored pretenure workshops providing access to various information facilitating the success of this transition: research, teaching and academic service to the department, the school, the university and/or the discipline, as well as written and oral communication, negotiation, mentoring and work/life balance (Mavriplis et al., 2005).

Candidates for an academic STEM career can be thought of moving along a pipeline from grade-school to high school to college to advanced degrees to academic positions. The critical juncture to tenure-track professorship is indeed one of the major leaks in the welldocumented "leaky pipeline" (Blickenstaff, 2005): for example, as women were awarded $44.6 \%$ of the science and engineering doctorates in the US in the period of 1996-2005, only $35 \%$ of the tenure-track science and engineering positions in 2006 were held by women with less than 10 years since their doctorate (NSB, 2010). These numbers clearly indicate a leak in the system that, admittedly, could be due to many other plausible reasons: for example, women do not see professorship as an attractive career (Thomson, 2000) or women make other career choices and/or other life choices. Still, a number of women report frustration with advancement in the system. Many report difficulties securing positions, even interviews, difficulties finding positions in the same geographical location as their partners, and finding fulltime employment leading to permanent positions. Many drop out or are marginalized (Sandler, 1992, MIT, 1999, Mason and Goulden, 2002, Trower and Bleak, 2004) at this stage.
Preston (2004) reports in her survey of I,688 scientists (not including social scientists) and engineers that women leave science careers in greater numbers than men: in particular, women who had the university as their intended place of employment exited employment altogether at a rate of $14 \%$ vs. $3.7 \%$ for men, and exited to another occupation at a rate of $18 \%$ vs. $15 \%$ for men. Married women with PhDs in her sample were $11 \%$ less likely than single women to work in science, whereas single men were $12 \%$ more likely than their single counterparts to stay in STEM. Interestingly, having children seemed to have no effect on this group. Similar statistics are available from the University of California system's survey of 4,459 faculty members conducted by Mason and Goulden (2002). Their findings do, however, show that the effect of children is significant: women are less likely to have children in the pre-tenure stage than men, suggesting that women are delaying marriage and children and reinforcing the perception that to make it in this field a woman cannot be successful and raise a family at the same time.

Certainly, the dual career problem of highly educated and ambitious women married to highly educated and ambitious men has been well documented (McNeil and Sher, 1999, Wolf-Wendel et al., 2003), confirming the above statistics. The data shows that more women scientists are married to men scientists, and that the task of finding employment in the same geographical area as their spouses is especially problematic in academia.

While family matters may seem to account for the lion's share of the leakage at this stage, a closer look reveals otherwise. Preston's study (2004) determined that a discontent with science - the way it is conducted and the interactions they have on the job - is a more likely determinant for an exit from scientific careers. The female respondents of her survey differentiated themselves from the men with the following reasons for leaving science (among others): looking for more interesting work out of science, lack of a mentor or guidance, hours required are too long (but demands were not deemed too severe), science and engineering unfriendly to women. Cathy Trower, research director of the Collaborative on Academic Careers in Higher Education (COACHE) that has surveyed more than 130 institutions with the TenureTrack Faculty Job Satisfaction Survey, has also found that female STEM faculty are less satisfied than their male 
colleagues with how well they "fit" in their departments, opportunities to work with senior faculty, perception of fair treatment of junior faculty in one's department, and institutional support for having a family while on the tenure-track (Hill et al., 2010).

Some effort and programming have been established to attend to this leak. The MIT study (MIT, 1999) established baseline data on some of the issues addressed by women in academic STEM fields. The National Science Foundation ADVANCE grants for institutional change are directed at reviewing and refining such practices as university policy on dual career family appointments and tenure clock changes. Our ongoing (and replicated) FORWARD to Professorship workshop (Mavriplis et al., 2005) focuses on the support and information needed for these talented women to secure tenure-track positions and thrive in them.

\section{Career Model for Women in Academia}

The academic model for advancement in scientific disciplines includes a preference for a lock-step career progression from undergraduate to graduate education, to a postdoctoral position and then to an academic position with continuous employment, especially as relates to tenure-track positions, and large amounts of contact time especially in lab-based disciplines, accompanied by an expectation that one's career is "made" in one's 30s (with the perception that one catches that wave or misses the boat), and lastly that one's career is measured in earning power. This model clearly does not fit with: I) women's biological clocks which favor this same chronological career establishment phase of their life as the time to give birth to and raise children; and 2) men and women's potential desires to establish a family and/or pursue other interests in this creative time of their lives. This model disproportionately penalizes women and contributes to the slow advancement of women, among other consequences. Many women persevere in the field choosing their own path, but the obstacles are significant. Women more often than men may find themselves in a "career break" or "gap", which we will define, for the purposes of this study, as a time without the full-time employment necessary to lead them toward progress in their chosen field or career. Because of the lock-step nature of academic STEM careers, part-time employment is not considered to be a step toward advancement and is often viewed as a sign that a candidate is "not serious" about his or her career. The break may be "voluntary" (e.g. one may decide to take a break to pursue other interests or have a child) or "involuntary" (e.g. inability to find a position or illness). Sometimes, though deemed "voluntary" by the selfreporter, the decision may have been heavily influenced by outside pressures such as family concerns, social upbringing, difficulty finding a position, difficulty coordinating jobs with a family member's job, etc. Hewlett (2007) points out that women have a different "value position" than men and "highly qualified women tend to see a tight - and guilt ridden - connection between work commitments and family well being." As the break does not fit with the traditional lock-step model, we bring attention to the break as a "gap" that may widen as time goes on and ask women to "mind the gap" if they intend to return to their chosen careers.

\section{Why Women Leave Academic Careers}

Little is known about the numbers and attitudes of women who leave the academic pipeline, beyond the anecdotal evidence, which is considerable. Studies concentrate on those remaining in the pipeline, as these people are easier to locate for surveys. Preston's survey (2004) mentioned above and Seymour and Hewitt's study (1997) of undergraduates leaving the sciences are among the few documented data studies of those leaving the field. Even so, these studies do not reach those who are unemployed or untraceable due to changing fields.

Women are either pushed or pulled into the gap, a concept of career interruption noted by Hewlett (2007). Women are pulled into the gap seeking fewer workrelated responsibilities and flexible work hours as they address their family needs - be they raising children, accommodating spouses' careers or caring for elderly family members. Women are also pushed away when they determine that their STEM work is not satisfying or that advancement seems unattainable (Preston, 2004). As Hewlett points out, in reality the intertwining of the push and pull factors often leads women to take the definitive step of leaving.

The purpose of the present study is to document the plight of STEM doctoral women who find themselves in a career break and are encountering difficulties re-entering 
the academic pipeline. This paper reports the results of an exploratory, qualitative research study carried out from mid-2008 until end of 2009 with the aim to establish an understanding of the reasons why women enter a career break or gap, what their challenges are while in the gap and what, if anything, they feel could change the reasons why they entered the gap or improve their possible reentry into their academic career path in their chosen STEM field. Facilitating re-entry will help recoup the tremendous national, institutional and personal investments made in their highly specialized education. In order to study more closely the situation of STEM doctoral women at the tenure-track juncture, we tapped into the pool of exiting STEM doctoral women we could reach through our ongoing FORWARD to Professorship workshop (Mavriplis et al, 2005) attendees and related contacts.

\section{Methodology}

\section{a. Procedures}

A survey instrument (approved by the George Washington University Institutional Review Board) was developed to answer some of the questions relating to women in STEM career breaks. Participants in this study were asked 33 questions relating to their backgrounds, experiences in the break, and their outlooks for the future. We wanted to know how they viewed themselves before entering the gap and what challenges and benefits they found while they were in the gap. Questions asked included: how they found themselves in the break, what were the levels of satisfaction with and opportunities for advancement in previous employment, the intended length of the break, any problems associated with the break, their needs to smoothly return and concerns about returning to their career. Survey participants have been recruited on the basis of their response to announcements sent out on list-servs for women in scientific fields, notices in professional journals and magazines, and through personal contacts with our workshop participants. Respondents to our email solicitation were briefed on the purpose of the study and if they agreed to participate, a telephone interview was arranged. Telephone structured interviews lasting 15-30 minutes were conducted by graduate students in psychology trained to do so.

\section{b. Subjects}

This preliminary study restricts itself to STEM doctoral women with a minimum of one year post-PhD full-time employment in a STEM field, less than five years since their last employment and an intention to reenter the job market to pursue an academic career.

During 2008 and 2009, 15 women fitting the above criteria agreed to participate and were interviewed. All but two were living in the United States - one in Canada and one in Australia. They held doctoral degrees in the following subjects: atmospheric science, astronomy, astrophysics, bio-chemistry, chemistry and geochemistry, computer science/engineering, geology, mechanical engineering, oceanography, pharmacology, physics and physiology. The women's ages ranged from 33 to 59 and most had received their doctoral degree between 2000 and 2009 (Table I). The typical route observed in these respondents' careers was a doctoral degree followed by a post-doctoral position for an average of two years though one woman had worked for a major company in their research division and one had been a national laboratory fellow. The subjects reported, on average, they felt that they were in charge of their decision to enter the gap.

Other characteristics of the group detailed in Table I are averages and ranges of responses. Most of the women seemed to be quite satisfied (an average rating of 4.9 on a scale of $1-7$ with 7 being very satisfied) with their last full-time position before entering the gap. They also found the positions to be quite demanding of their time (an average rating of 5.0 on a scale of $1-7$ with 7 being very demanding), yet saw little opportunity for advancement in those positions (an average rating of 3.0 on a scale of I-7 with I being no opportunity and 7 being a great deal of opportunity). Most of the respondents had not been in the break for long (with an average of less than I year). 


\begin{tabular}{lccc}
\hline Characteristics & Average & Range & \# respondents \\
\hline Age & 38.2 & $33-59$ & 15 \\
Years since PhD & 7.5 & $1-32$ & 15 \\
$\begin{array}{l}\text { Years in last full-time position } \\
\text { How satisfied with their last job } \\
\quad \text { (scale I-7) }\end{array}$ & 3.1 & $1-13$ & 12 \\
$\begin{array}{l}\text { Opportunity for advancement } \\
\text { in that position (scale I-7) }\end{array}$ & 3.9 & $2-7$ & 12 \\
$\begin{array}{l}\text { How demanding of your time } \\
\quad \text { was the job (scale 1-7) }\end{array}$ & 5.0 & $1-6$ & 12 \\
$\quad$ & $2-7$ & 13 \\
\hline
\end{tabular}

Table I. Characteristics of the Interviewed Women in Career Breaks. (Scales of I-7 with 7 being very satisfied / a great deal of opportunity for advancement / very demanding of your time.)

\section{Findings}

\section{- Respondents' Satisfaction with their Career prior to the Gap}

As noted in Table I, before these women moved into the gap, the majority (at least nine) of the 15 women surveyed indicated that they were satisfied with last their job, they felt that they worked extremely hard and that the level of opportunity to advancement in that position was low. When asked what part of their position they enjoyed the most, research and working on research teams, as well as working with students were common replies. Typical of the replies was one from a geo-chemist who reported that she "enjoyed the applied aspect of the job, working towards a specific clean-up goal to better the world."

\section{- Respondents' Dissatisfaction with their Career prior to the Gap}

Respondents were also asked what part of their positions did they least enjoy. There was much less agreement about the parts of the position that they did not enjoy. They noted isolation (especially those working on computer models and those who tele-commuted), the political environment, the lack of freedom to select a research topic, administrative work and for some the allor-nothing atmosphere of the position leaving no time for a meaningful work-life balance. While advancement in a position is important, most respondents did not seem concerned with pathways to advancement or finances at that point in their careers.

\section{- Drivers of the Entry into the Gap and Issues Faced while Being in the Gap}

Once we established what life was like for the women before they entered the gap, we wanted to know what drew them into the gap and what issues they faced in the gap. For all but one of the women interviewed, a family issue drew them into the gap for a career break. Nine were related to pregnancy, child-birth and child care, two related to husbands relocating, two experienced both a pregnancy and a relocation, and one went into the gap because a parent was terminally $\mathrm{ill}^{8}$. One respondent took a voluntary career break because she was "bored". Most women for whom the career break was solely due to having a child reported that they felt they were in charge of the decision and that the decision to take a career break was in fact a good decision. This was true even for the women who reported that the pregnancy was not "planned". Even the women who took a career break because of issues outside of their control or for complicated reasons (e.g. a new baby and the end of a post-doctoral appointment and the need to follow a spouse) report that they miss the laboratory and/or stimulation but are enjoying time with their baby. One respondent said:

\footnotetext{
${ }^{8}$ Not every subject answered every question.
} 
I felt peer pressure to work 60 hours a week, but having a baby I only worked 45 hours and felt like a slacker. And this meant that I couldn't progress as successfully as those who put in 60-hour weeks. I didn't like feeling "not the best", because I was used to being the best in school.

Being in the gap has its own concerns. One respondent summed it up as follows:

It is uneasy not knowing about the professional future. I could be a lecturer full-time, but a tenured position is unlikely. I am taking a huge step back in my career by taking a break. I am concerned about staying visible in the field. I don't see examples of people doing that. It's a no man's land. I expect a permanent career setback. Maybe I am being a bit too dramatic about it at the present moment.

We wanted to know what it felt like to be in the gap. Our respondents noted that they felt it would be a steep path to return from science. They felt distant from their academic/discipline peers. While new peer groups arise (e.g. other stay-at-home moms), the fact that these educated women had invested so much time to this point in their career only to find themselves without a peer group was difficult.

\section{- Confidence, while in the Gap, in their Skills in a Variety of Areas}

These skills included (see Table 2): up-to-date skills in their discipline, writing a research proposal, negotiating salaries, performing research and teaching. The respondents reported that they felt their skills were current. Similarly, they reported confidence in their research and teaching skills; we note, however, that the women in this study were in the gap (on average) only about a year and expect that this attitude could change as the length of time in the gap lengthens, as expressed by Preston's (2004) study participants. The women we interviewed felt less confident when it came to the soft skills they might be called upon to use to secure a position: writing a research or teaching statement as well as negotiating for a salary or start-up package.

\begin{tabular}{|c|c|c|c|}
\hline Intentions / Perceptions & Average & Range & \#respondents \\
\hline \multirow[t]{3}{*}{ Was the break a good decision } & $\mathrm{N} / \mathrm{A}$ & II Yes & 14 \\
\hline & & 2 Forced $^{9}$ & \\
\hline & & I Unsure & \\
\hline Planning to return to work & yes & unanimous & 14 \\
\hline Planning to return to STEM field & yes & unanimous & 14 \\
\hline $\begin{array}{l}\text { Confidence in up-to-date skills in field } \\
\text { (scale I-5) }\end{array}$ & 4.2 & $3-5$ & 14 \\
\hline $\begin{array}{l}\text { Confidence in writing research proposal } \\
\qquad \text { (scale I-5) }\end{array}$ & 3.4 & $2-5$ & 14 \\
\hline $\begin{array}{l}\text { Confidence in negotiating salary } \\
\text { and start-up funds (scale I-5) }\end{array}$ & 3.3 & $2-5$ & 12 \\
\hline $\begin{array}{l}\text { Confidence in performing research } \\
\qquad \text { (scale I-5) }\end{array}$ & 4.1 & $2-5$ & 14 \\
\hline $\begin{array}{l}\text { Confidence in being an effective teacher } \\
\text { (scale I-5) }\end{array}$ & 4.5 & $3-5$ & 14 \\
\hline
\end{tabular}

Table 2. Intentions and Perceptions of the Interviewed Women in Career Breaks. (Scales of I-5 with 5 being very confident.)

\footnotetext{
${ }^{9}$ Respondents indicated that it was not their choice to take a break.
} 


\section{- Factors Impacting the Respondents' Intentions to Return from the Gap}

All of the women reported (see Table I) they intended to return to work as soon as the reasons that brought them into the gap were resolved. We asked about what they thought were the helping or inhibiting factors for a return from the gap. One respondent said it best as she recounted a few issues to be dealt with:

An inhibiting factor - underdeveloped networks. A big factor - If [a woman] had a child, it is likely that her ties with professional communities will lessen, as opposed to other networks (such as other moms). Also, it is harder to come back as a woman, because as a woman you are less welcome in STEM fields to begin with (general attitude). There are no visible successful examples of non-linear careers for STEM women. Only non-breaking careers are publicized as successful examples.

The respondents noted not only the isolation mentioned above, but also the negative biases in the disciplines expressed toward those who seek to raise a family, as the following quote denotes:

It's difficult for any gender to be out of science, it's hard to keep up. You fall out of social networks, keeping up appearances is important. I took 6 months off for a baby, and it was hard to come back. People who have families sometimes are seen as "worse" scientists, i.e. they don't work hard enough (only 8 hours a day and not 12-14). When I had my first son, I was working harder than in my entire life trying to combine work and family, but nevertheless I was seen as someone who is not doing a good enough job. It was very difficult.

Most of the women in this study were in the 33-43 year old range and so most had recently dealt with the decision to have children. They noted that this decision comes at about the same time the decisions about post-doctoral and tenure-track positions are being addressed as well. The intersection of these two decision points made the career gap even harder and lonelier. One woman noted that:
At 30 you have all the big decisions at once: career and kids. And it is usually the woman who has to make the sacrifice and that her career is second and then you have to adapt, and once you pick "adapt career" it is hard to get back.

While these women were still in the gap, they all reported they wanted to return to STEM and we thought they might have ideas on what would make it easier for them to do so.

\section{- What Changes Could Be Made within the STEM Culture to Make It Easier for Women to Return from the Gap?}

Suggestions ranged from the creation of seminar series to inform women about the issues looming ahead, to structural changes in recruitment and retention. One said:

Many applications for jobs ask for information on the past five years of experience. So, if you were on a break for the past five years or a part of it, you have a problem, i.e. no place to describe your best experiences. It should be changed to "provide description of any five years of your career" or something of that extent.

Speaking also about the evaluation process for retention, one woman noted:

One should be evaluated on your complete skill set, not their latest paper. The "publish or perish" principle is not effective. It affects women more, because they have to take care of families and spend more time on it. Other skills (like management or teaching skills) should be taken into account.

The respondents admitted that the systemic solutions are complex and that one solution could not possibly fit all the various situations women find themselves in. One woman summed it up for everyone:

I think there are a lot of small changes that would make big impacts. I) I think women are disproportionately asked to do education and outreach work, which then diminishes their opportunity to do research. Women often want to 
do this outreach so that they can present role models to youngsters out there, etc, but it eats into all that research time. Upon the return from a career break, employers and supervisors need to protect the woman from an overload of invisible work. 2) I think that senior advisers need to be careful and aware of the difficulties surrounding family creation timing. Support for women taking time off (a break) to have children needs to be verbal - loud and clear - from people in positions of power. I verbally asked the people offering my prestigious postdoc, "If I turn this position down this year due to just having a child, what are my chances of getting another offer next year?" It wasn't an official agreement, but asking that question, and getting a supportive answer made a difference - it gave me confidence to go ahead with my career break. Women, also, need to be very clear about what they want and what would benefit them. 3) Again, having examples of peers and role models who have taken a break and yet still been successful in their jobs is very important.

\section{Analysis}

This rich set of responses to the more than 30 survey questions provides us with insight into the stresses that bring women into the career gap, the challenges and benefits of being in the gap and ideas about how academic STEM fields might smooth the path for those returning from the gap.

\section{- Respondents' Satisfaction and Dissatisfaction with their Career prior to the Gap}

The fact that these women reported that their positions were highly demanding of their time and energy, and at the same time they felt that there was little opportunity for advancement, relates well to other studies about the culture of STEM academic careers (Preston, 2004, Hill et al., 2010). Comments from women in the gap also resonate with Hewlett's study (2007) about the value position of work and family. In her report on faculty satisfaction, Trower noted that "The lab knows no official stop time - it's an unrelenting 24/7. It's difficult to just pack up and go home." (Hill et al., 20I0, page 7I).

\section{- Drivers of the Entry into the Gap and Issues Faced while Being in the Gap}

Other researchers report (e.g. see Mason and Goulden, 2002) that balancing family and work is difficult at best. Even though one third of the women in our survey reported that they "had to" enter the gap, that they had no alternative, all reported being happy with the decision. Those who entered the gap because of children were satisfied that they chose children over career at that moment and reported enjoying their children very much.

\section{- Factors Impacting the Respondents' Intentions to Return from the Gap}

The isolation noted by some of the respondents is confirmed by an Institute of Physics survey (IOP, 2004) where $52 \%$ of the institute members responding to a survey on career breaks (mostly women) reported feeling isolated during their break. Suggestions from that survey were to keep contact with the employer throughout the break and to have a proactive mentor, although most respondents had predominantly kept up with colleagues only. Certainly networking through professional societies and conference attendance as suggested below could attend to these feelings of isolation and help structure plans to return to an academic career.

\section{- Confidence, while in the Gap, in their Skills in a Variety of Areas}

There are a variety of skills necessary for obtaining an academic position. When we review the data on confidence and compare this group of women to women who were participants in the FORWARD to Professorship workshops (Mavriplis et al., 2005 and 20I0) (see Table 3), we see that those women who had the advantage of career development workshops that provide skills and information on what might lie ahead in the soft skill areas of grant proposal writing, securing funding and negotiating for positions and start-up packages, demonstrated much more confidence in these areas than did the women in the gap. Participation in career development workshops before a woman enters the gap or while she is pursuing her advanced degree might reduce the stress of being in the gap and help prepare the woman for re-entry. 


\begin{tabular}{lll}
\hline Confidence in & $\begin{array}{l}\text { \% of women in } \\
\text { career breaks reporting } \\
\text { high confidence }\end{array}$ & $\begin{array}{l}\text { \% of workshop } \\
\text { attendees reporting } \\
(\mathbf{n}) \text { \# respondents }\end{array}$ \\
\hline $\begin{array}{l}\text { Writing research proposal } \\
\begin{array}{l}\text { Negotiating salary \& } \\
\text { start-up funds }\end{array}\end{array}$ & $50 \%(n=13)$ & $90 \%(n=62)$ \\
$\begin{array}{l}\text { Acquiring funding for } \\
\text { research }\end{array}$ & $35 \%(n=12)$ & $85 \%(n=59)$ \\
\hline
\end{tabular}

Table 3. Comparison of Confidence Levels of the Interviewed Women in Career Breaks with FORWARD to Professorship Workshop Attendees.

\section{- What Changes Could Be Made within the STEM Culture to Make It Easier for Women to Return from the Gap?}

The bigger question that the survey addressed is what can be done to address the gap before someone feels that there is no alternative to entering the gap and what can be done to make reentry from the gap easier. In either case, the effort would be to legitimize breaks.

The respondent quoted above who noted that a change to hiring practices to address the gaps in her resumé, resonates with Hewlett's (2007) suggestion an "arc-ofcareer" flexibility, whereby women in the gap could be able to re-enter the career on a different path from those who are just entering the field. If the networks and supports are in place during the gap, women will be able to mark their most productive five years, rather than their last five years as a sign of their merit and ability.

In the past few years some very positive work has been accomplished in several arenas to improve the advancement and retention of women in STEM academia. First of all, the NSF ADVANCE grants have spurred on institutional transformation across the country through a number of creative initiatives (for a summary of some of the projects see Stewart et al., 2007). Of note, we mention University of Wisconsin's WISELl's work in developing best practices for faculty search committees (Sheridan et al., 2007) which could have an impact on women returning from career breaks. In their workshops and accompanying booklet, WISELI trainers promote the use of objective criteria for evaluation of candidates that would allow for breaks in their experience calendar.

The Canadian granting agency for STEM fields, the Natural Sciences and Engineering Research Council, requires in every grant application a personal data form that allows for some flexibility that would benefit people with a variety of non-traditional paths. It requests a description of the applicant's "most significant contributions to research over the last six years. Contributions made more than six years ago but for which the impact is being felt now may be included. For non-university research and training, contributions over the last ten years may be included." The form also provides for "explanations of any significant delays in research activity or in disseminating research results (e.g., parental leave, bereavement, single parent situations, illness, extraordinary administrative duties or other circumstances)" (NSERC, 2010).

Recently some career reentry grants and fellowships have become available. National Institutes of Health (NIH) career reentry supplements support postdoctoral researchers to restart their biomedical and behavioral research careers after a break of one to eight years. Candidates must have been in a postdoctoral or faculty position at the time they left active research. The funding is through a supplement to an existing $\mathrm{NIH}$ grant for a principal investigator who has at least two years remaining.

The American Physics Society recently announced the $M$. Hildred Blewett Scholarship to support early-career women in the United States or Canada who have taken a career break for family reasons. The Blewett candidate must have 
an affiliation with a research-active educational institution or national lab. The American Association of University Women offers postdoctoral research leave fellowships that do not require an affiliation for women who have completed their doctoral degree by a specified date. In the United Kingdom (UK), the Daphne Jackson Trust offers reentry grants for UK residents in science, engineering, and technology careers who have taken a career break of at least two years. Similarly, the UK Wellcome Trust Career Re-entry Fellowships, since 1994, have provided funding for biomedical postdoctoral researchers who have taken career breaks of at least two years. While these initiatives offer some hope for women in very select fields and only at the postdoctoral level, we urge other societies to offer similar support in a variety of STEM fields and career levels.

The suggestion then is that addressing career breaks is about two prongs: (i) addressing women's needs; and (ii) addressing the STEM culture.

\section{(i) Addressing Women's Needs}

Women's needs include information on what a career path might be like and meeting other women who have faced these issues to learn various coping mechanisms. Helping women in a STEM career break is about more than just money. Our discussions with these women indicated that most women had or were taking a break to raise their family and that it's extremely hard to maintain a successful career in academia and also raise a family. They noted that keeping a foot in the door by either keeping in touch with advisors or doing some part-time work seemed to help them return to their career. They had very favorable attitudes towards programs that might help them secure part-time work or maintain or create a social network for "gap" women. Clewell and Campbell (2008) noted that exposure to women who are well-established in the field helps break down the gender barriers that work against women's persistence in STEM disciplines. Moreover, women engineers report that mentoring relationships provided them with a better understanding of the educational climate and a clearer picture of expectations for performance and other elements of the professional work environment (Kahveci et al., 2006, Brainard and Ailes-Sengers, 1994).

Noting that in some recent years just as many women as men started out in science, Nobel laureate Elizabeth
Blackburn (2009) argued that a few adjustments could help to even the career playing field. Blackburn said a more flexible approach to part-time research and career breaks would help women continue to advance their careers during their childbearing years. "I'm not talking about doing second-rate quality science, far from it," she said. "You can do really good research when you are doing it part-time."

\section{(ii) Addressing the STEM Culture}

Addressing the STEM culture relies on various changes to hiring practices and some practices to sustain scientists during a career break. Some of our respondents noted that they felt isolated both in their position and in the gap, but the current structure of professional societies and conferences does not readily support their participation. For example, if they are not working, the cost of membership or attendance is quite prohibitive. While society members often receive reduced dues rates once they are retired, such reductions are not readily available for those in the gap. It is more appropriate for STEM societies to arrange these types of affordances across the board, rather than to expect an individual woman to ask for help. We know from other studies that women often find asking not quite so simple. As a COACHE survey responder noted "Stopping for any period of time, to take advantage of stop-the-tenure-clock leave for example, could be deadly to your research program.” (Hill et al., 20I0, page 7I)

We recommend that professional societies create a reduced rate structure for individuals in a gap and extend that reduction to conferences as well. While we have not performed an exhaustive survey, we note that only a handful of societies offer reduced membership rates for unemployed persons, and for these they often require a statement that they are actively seeking work. We were able to find two societies, IEEE and the National Center for Women \& Information Technology (NCWIT), that offer reduced rates for those unemployed for family reasons. We suggest other professional societies follow suit.

Finally, health care coverage and child care changes in the STEM culture would provide the support for women before they enter the gap and as they return to the workforce. Health care changes address some of this, but it is worth noting that some conferences provide onsite child care or at least indicate the availability of babysitters. This would go a long way to keeping women connected.

ISSN: 07I 8-2724. (http://www.jotmi.org)

Journal of Technology Management \& Innovation (C) Universidad Alberto Hurtado, Facultad de Economía y Negocios 


\section{Conclusions}

This exploratory study has revealed some truths about career breaks for women in STEM. Highly trained STEM doctoral women, who find themselves in career breaks, voluntary or involuntary, do want to return to their careers, have confidence in their research and teaching skills, but see formidable obstacles in their paths to return. While there is not one "gap" path and there is not one solution that would fit all women, there are commonalities that would support women in avoiding the gap and smooth their return from a STEM career break.

There are actions to be taken both before and after women complete their advanced education. For those who are still working on their degree, workshops and discussions that raise the career gap issue and encourage women to construct a work/life balance as they plan their career would be helpful. Simply knowing what might lie ahead and having time to think about what one might do in the face of a career gap decision is important. Such discussions and workshops could include a variety of models of how others have handled these decision points in a career.

For those already in a career and faced with a gap or for those in the gap, policies by universities and professional societies that acknowledge the stresses and challenges of a career gap are invaluable. Some changes, such as better health care, maternity leave and child care apply to the times before women enter the gap or the time when they are ready to reenter their career path. Such changes would have enabled women to stay in their positions or return smoothly.

These changes relate to issues of work-life balance and to STEM structure. While this study focused on women, as the expression goes, these tide changes could lift all boats, not only the ones piloted by women.

\section{Acknowledgments}

This work is supported by a US National Science Foundation (NSF) ADVANCE grant (0930126). Any opinions, findings and conclusions or recommendations expressed in this material are those of the authors and do not necessarily reflect the views of NSF. We thank the survey participants and all those who helped to distribute the call for participants.

\section{References}

BLACKBURN, E. (2009). Nobel Laureate: Fix the Scientific Career Ladder and Let Women Climb, December 2009. http://blogs.discovermagazine.com/80beats/2009//2/07/no bel-laureate-fix-the-scientific-career-ladder-let-womenclimb/ [Accessed April 4 2010].

BLICKENSTAFF, J.C. (2005). Women and science careers: leaky pipeline or gender filter? Gender and Education, 17(4), October 2005, 369-386.

BRAINARD, S.G., Ailes-Sengers, I. (1994). Mentoring female engineering students: A model program at the University of Washington. Journal of Women and Minorities in Science and Engineering, I (2), I23-135.

CLEWELL, B.C., Campbell, P.B. (2008). Taking Stock: Where We've Been, Where We Are, Where We're Going. August 10, 2008. http://www.urban.org/ url.cfm?!D=1000779 [Accessed April 4 2010]

HEWLETT, S. A. (2007). Off-Ramps and On-Ramps: Keeping talented women on the road to success. Harvard Business School Press, Cambridge.

HILL, C., Corbett, C., St. Rose, A. (2010). Why So Few? Women in Science, technology, Engineering and Mathematics. AAUW, Washington.

INSTITUTE OF PHYSICS (IOP) (2004). Career Breaks 2004. IOP, London.

KAHVECI, A., Southerland, S. A., Gilmer, P. J. (2006). Retaining undergraduate women in science, mathematics, and engineering. Journal of College Science Teaching, 36 (Nov-Dec), 34.

MASON, M.A., Goulden, M. (2002). Do Babies Matter: The Effect of Family Formation on the Lifelong Careers of Academic Men and Women. Academe, NovemberDecember 2002, 88(6), 2I-27.

MASSACHUSETTS INSTITUTE OF TECHNOLOGY (MIT) (1999). A Study on the Status of Women Faculty in Science at MIT. The MIT Faculty Newsletter, Vol. XI, No. 4. 
MAVRIPLIS, C., Heller, R.S., Sorensen, C.C., Snyder, H.D. (2005). The "FORWARD to Professorship" Workshop, ASEE Paper 2005-I 352.

MAVRIPLIS, C., Beil, C., Dam, K., Heller, R., Sorensen, C., (2010). An Analysis of the FORWARD to professorship Workshop - What Works to Entice and Prepare Women for Professorship? In: Godfroy-Genin, A.S. (ed.) Women in Engineering and Technology Research: The PROMETEA Conference Proceedings. LIT Verlag, Berlin.

MCNEIL, L., Sher, M. (1999). Report on the Dual-Career Couple Survey, http://www.physics.wm.edu/ sher/ survey.html [Accessed March 31 20l0]

NATIONAL SCIENCE BOARD (NSB) (2010). Science and Engineering Indicators 2010, NSB 10-01, Arlington, VA: National Science Foundation.

NATURAL SCIENCES AND ENGINEERING RESEARCH COUNCIL (NSERC) (20I0). Form 100 - Instructions, http://www.nserc-crsng.gc.ca/OnlineServices-ServicesEn Ligne/instructions/100/e.asp [Accessed April 19, 2010]

PRESTON, A.E. (2004). Leaving Science: Occupational Exit from Scientific Careers. Russell Sage Foundation, New York.

SANDLER, B.R., (1992). The Campus Climate Revisited: Chilly for Women Faculty, Administrators and Graduate Students. American Association of Colleges, Washington.

SEYMOUR, E., Hewitt, N.M. (1997). Talking About Leaving: Why Undergraduates Leave the Sciences. Westview Press, Boulder.

SHERIDAN, J., Fine, E., Winchell, J., Pribbenow, C. M., Carnes, M., Handelsman, J., (2007). Searching for Excellence \& Diversity: Does Training Faculty Search Committees Improve Hiring of Women?, American Society for Engineering Education (ASEE) 2007 Conference Proceedings.

STEWART, A., Malley, J., LaVaque-Manty, D., co-editors (2007). Transforming Science and Engineering: Advancing Academic Women. University of Michigan Press, Ann Arbor.

THOMSON, E.A. (2000). Study points to career/family concerns among women engineering faculty, Massachusetts Institute of Technology News Office, http://web.mit.edu/newsoffice/2000/women-0329.html

[Accessed March 31, 2010]

TROWER, C.A., Bleak, J.L. (2004). Study of New Scholars. Gender: Statistical Report [Universities]. Harvard Graduate School of Education, Cambridge, MA.

WOLF-WENDEL, L., Twombly, S., Rice, S. (2003). The Two-Body Problem - Dual- Career-Couple Hiring Practices in Higher Education. Johns Hopkins University Press, Baltimore.

\section{About the Authors}

Catherine Mavriplis (PhD) is an Associate Professor of Mechanical Engineering at the University of Ottawa. She has been principal investigator (PI) and co-PI on four NSF ADVANCE Grants to advance women in the professoriate and at leadership levels in academia. She has also worked on women's leadership in engineering industry, notably with Pratt \& Whitney Canada.

Rachelle Heller (PhD) is the Associate Dean for Academic Affairs at the Mount Vernon Campus of the George Washington University and a professor of computer science. Her research areas include the advancement of women and underrepresented minorities in the STEM fields as well as the role of computers in education and are the recipient of many grants in this area, most notably the three NSF ADVANCE awards for FORWARD To Professorship. She serves as the co-editor of the Computers \& Education journal.

Cheryl Beil (PhD) is Assistant Vice President of Academic Planning, Institutional Research, and Assessment at the George Washington University.

Kim Dam is the Director of Academic Planning and Assessment at the George Washington University.

Natalya Yassinskaya and Megan Shaw are graduate students at the George Washington University and performed the interviews.

Charlene Sorensen (PhD) is an Associate Professor of Chemistry and Chair of Chemistry and Physics at Gallaudet University. She has been co-PI on three NSF ADVANCE grants addressing the advancement of women and Deaf scientists in academia. 